\title{
O TESTE DE COMPREENSÃO ICONOGRÁFICA COMO FERRAMENTA DE AFERIÇÃO DA ALFABETIZAÇÃO VISUAL DE USUÁRIOS DIGITAIS
}

\section{THE ICONOGRAPHIC COMPREHENSION TEST AS A TOOL TO MEASURE THE VISUAL LITERACY OF DIGITAL USERS}

\author{
Patrícia Carrion ${ }^{1}$, M.Sc. \\ Ana Carolina Cruz ${ }^{2}$ \\ Mariana Fernandes ${ }^{3}$ \\ Manuela Quaresma ${ }^{4}$, D.Sc. \\ (1) Pontifícia Universidade Católica do Rio de Janeiro - PUC-Rio \\ e-mail:patriciac@aluno.puc-rio.br \\ (2) Pontifícia Universidade Católica do Rio de Janeiro - PUC-Rio \\ e-mail: cruzana.design@gmail.com \\ (3) Pontifícia Universidade Católica do Rio de Janeiro - PUC-Rio \\ e-mail: mariana.hazk@gmail.com \\ (4) Pontifícia Universidade Católica do Rio de Janeiro - PUC-Rio \\ e-mail: mquaresma@puc-rio.br
}

Palavras-chave: Alfabetização Visual, Teste de Compreensão, Usuários Digitais

O ritmo acelerado de inovação tecnológica destaca as questões da relação entre usuários, objetos e ambientes digitais, e, evidencia, no contexto das interfaces gráficas, a existência de uma Alfabetização Visual-Digital. O meio digital, construído pela intersecção de mídias e gêneros visuais distintos, exige dos usuários um conjunto específico de habilidades, visto que a instabilidade das interações digitais define uma dinâmica única entre designers, plataformas e usuários. Diante desse cenário, o objetivo geral desta pesquisa foi o de investigar o impacto da Alfabetização Visual, por meio da aquisição de repertórios, na experiência de usuários no acesso a dispositivos móveis. Nesta etapa em específico, foi definida uma técnica de avaliação a fim de mensurar o repertório visual dos sujeitos da pesquisa: o Teste de Compreensão Iconográfica.

\section{Key-words: Visual Literacy, Comprehension Test, Digital Users}

The rapid pace of technological innovation highlights the issues of the relationship between users, digital objects and environments, and, in the context of graphical interfaces, shows the existence of a Visual-Digital Literacy. The digital medium, built by the intersection of different media and distinct visual genres, requires people to develop a specific set of skills, since the instability of digital interactions defines a unique dynamic between designers, 
$16^{\circ}$ USIHC - Congresso Internacional de Ergonomia e Usabilidade de Interfaces Humano Computador

CINAHPA | 2017 - Congresso Internacional de Ambientes Hipermídia para Aprendizagem.

platforms and users. Hence, this paper proposed as an overall intention to investigate the impact of Visual Literacy, through the acquisition of repertoires, in users' access to mobile devices. To that effect, in this specific stage, an evaluation technique was defined with the purpose of measuring the visual repertoire of the research subjects: the Iconographic Comprehension Test.

\section{Introdução}

As tecnologias de uso pessoal estão em toda parte, entrelaçadas nos diversos aspectos da vida cotidiana. Presentes em dispositivos como smartphones, elas vêm promovendo

transformações maciças na sociedade, partindo da realização de tarefas diárias, da socialização entre pessoas, à aquisição de conhecimentos e à atenuação de barreiras geográficas. Dominantes no mundo das plataformas de computação, as telas dos dispositivos e suas interfaces gráficas certificam a presença de uma retórica visual. Isto posto que, ainda que se manifestando através de uma variedade de sentidos, o misto de tecnologia e design destaca a tendência humana aos estímulos visuais.

A existência dessa retórica no meio digital, ou seja, da apresentação extensiva de elementos visuais nas interfaces, atenta à necessidade do desenvolvimento de estratégias e conhecimentos específicos por parte dos usuários, um requisito para uma interação eficiente com dispositivos. Parte-se do pressuposto que, assim como ser digitalmente proficiente, aprender a interpretar os elementos visuais presentes no cotidiano e na esfera digital é uma habilidade essencial da contemporaneidade.

Quando se fala em usuários, discute-se essencialmente uma pluralidade de perfis, construída por diferentes origens, idades, contextos e níveis de instrução. Da mesma forma que essas variáveis são pertinentes para estudo, defende-se neste artigo que a proficiência visual dos indivíduos também deve ser considerada quando se discorre sobre Alfabetização Digital. Haja vista que essa alfabetização é essencial à Interação Humano-Computador, propôs-se como objetivo geral pesquisar o impacto da compreensão visual, por meio da aquisição de repertórios, na experiência de usuários no acesso a dispositivos móveis como smartphones. Esse objetivo, por sua vez, desdobrou-se neste artigo na investigação e classificação de tipos de usuários em níveis de repertórios visuais, com a finalidade de estabelecer, em etapa subsequente, o impacto da Alfabetização Visual sobre a Alfabetização Digital. Além disso, buscou-se aqui medir como a variável Alfabetização Visual difere para grupos distintos de pessoa. Para tanto, os dados obtidos foram avaliados por meio de ANOVAs, ou Análises de Variância.

\section{Método}

Ao se vislumbrar as evoluções digitais, é factível a prevalência da interação através da tela, ao menos no que diz respeito aos dispositivos de uso pessoal. Computadores desktop, smartphones, tablets e correlatos em muito dependem de símbolos gráficos a fim de informar o usuário quanto aos caminhos na navegação. O usuário, por sua vez, demanda de uma compreensão da estrutura da interface gráfica, das formas como se acessa e se introduz informações no sistema, das abstrações que apontam ao significado de um ícone, de um feedback ou demais alertas e elementos visuais. Com essa compreensão da leitura visual, indivíduos se mostram capazes de pensar como cada propriedade da estrutura da interface se relaciona hierarquicamente, o que se configura numa Alfabetização Visual.

Se no contexto das tecnologias digitais o usuário demanda de habilidades visuais singulares características de uma alfabetização visual/gráfica, por conseguinte, é congruente traçar um paralelo entre essa alfabetização e o conceito de proficiência digital. A fim de entender como a Alfabetização Digital se associa com a Alfabetização Visual concluiu-se necessária a convergência de dois testes. O primeiro, tratado neste artigo e denominado Teste de Compreensão Iconográfica, procurou avaliar como os
Realização:

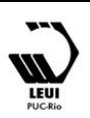




\section{$16^{\circ}$ \\ ERGODESIGN USIHC CINAHPA}

participantes interpretam elementos visuais, mais especificamente ícones, de interfaces gráficas digitais. Para tanto, trabalhou-se com a noção de repertórios. Os repertórios interpretativos visuais, sejam eles individuais ou pertencentes a um grupo homogêneo de indivíduos, são imprescindíveis à construção de sentido aos símbolos gráficos. Uma determinada sociedade pode ser avaliada, entre diversos aspectos, pela compreensão comum de certos sinais visuais. Deduz-se, portanto, que a Alfabetização Visual contempla inúmeros repertórios, e, no que concerne a esta pesquisa, trabalhou-se como o conceito de repertórios visuais no âmbito digital. Após os resultados do Teste de Compreensão Iconográfica, testes futuros buscaram aferir a influência dos repertórios dos sujeitos da pesquisa no desempenho destes em um Teste de Usabilidade.

\section{Teste de Compreensão Iconográfica}

O Teste de Compreensão teve como finalidade detectar o grau de entendimento correto dos símbolos, sendo um procedimento imprescindível no desenvolvimento de imagens para informação pública [FORMIGA, 2002]. Neste estudo, porém, o objetivo fora mensurar os níveis de repertório visual de sujeitos com características distintas como idade, experiência acadêmica, e assim por diante -, e não as variantes de um determinado referente, como acontece de modo geral. Todavia, ainda que optando por não despender a mesma rigidez dos testes do gênero, buscou-se fundamentação nas regras de aplicação desse método para a coleta e análise de dados.

Ao elucidar como indivíduos com diferentes repertórios visuais compreendem os ícones de interfaces gráficas de dispositivos digitais, o teste se propôs à classificação dos sujeitos da pesquisa em dois níveis de Alfabetização Visual: em uma extremidade, esperava-se encontrar os participantes com alto repertório visual, e em outra, os com repertório mais limitado. Essa segmentação se fez crucial ao recrutamento dos voluntários do Teste de Usabilidade, uma vez que se buscou, em caráter mais extenso, traçar a relação entre a Alfabetização Visual dos participantes com o desempenho destes em $16^{\circ}$ Ergodesign - Congresso Internacional de Ergonomia e Usabilidade de Interfaces Humano Tecnológica: Produto, Informações Ambientes Construídos e Transporte

$16^{\circ}$ USIHC - Congresso Internacional de Ergonomia e Usabilidade de Interfaces Humano Computador

CINAHPA | 2017 - Congresso Internacional de Ambientes Hipermídia para Aprendizagem. interações no contexto das tecnologias digitais, em particular os smartphones. Em suma, a proposta do Teste de Compreensão se desdobrou nos seguintes objetivos específicos:

1. Medir os acertos e erros dos sujeitos da pesquisa quanto ao conhecimento de ícones utilizados em um conjunto de sistemas operacionais específicos e suas GUIs;

2. Classificar tais indivíduos em dois extremos de Alfabetização Visual;

3. Averiguar o impacto de variáveis sociodemográficas no repertório visual dos sujeitos da pesquisa.

Para a efetuação do teste, 48 voluntários foram apresentados a 40 ícones digitais. De acordo com Formiga [2002], testes dessa natureza exigem em torno de três a seis variantes para cada referente. No entanto, nesta pesquisa optou-se por trabalhar apenas com ícones comumente utilizados em tecnologias digitais, mais especificamente os presentes em duas populares plataformas, a Apple e a Microsoft - e seus respectivos sistemas operacionais para computadores desktop -, visto se tratarem das mais utilizadas no Brasil e no mundo [NET MARKET SHARE, 2016]. Por esse motivo, foram selecionadas apenas duas variantes para cada referente, uma representante de cada plataforma.

No que tange à noção de repertórios, a escolha de ícones se limitou apenas ao contexto dos dispositivos de mesa (desktop) a fim de circunscrever o escopo do estudo, e partindo da premissa de que porção significativa das representações gráficas presentes em aplicações móveis provêm dos computadores de uso pessoal. Uma vez que o foco do teste estava em testar o repertório visual dos sujeitos, e não as variantes dos símbolos, acredita-se que as estratégias aqui estabelecidas foram suficientes para determinar o nível de Alfabetização Visual dos indivíduos, além de tornar as sessões de teste mais rápidas e dinâmicas.

\subsection{Participantes}

Para avaliar os níveis de Alfabetização Visual em
Realização:

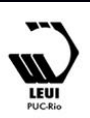




\section{$16^{\circ}$ \\ ERGODESIGN USIHC CINAHPA}

relação aos repertórios no âmbito digital, foram estipulados alguns critérios à seleção dos participantes. A princípio, todos deveriam ser usuários de smartphones, visto que o Teste de Usabilidade subsequente seria realizado com um dispositivo do tipo. Além disso, os sujeitos deveriam possuir o mesmo grau mínimo de escolaridade, nível superior completo ou cursando em qualquer área, com a intenção de que graus de escolaridade muito distintos não interferissem no controle da amostra e, por consequência, nos resultados finais dos testes e da pesquisa.

Em relação às características básicas dos participantes, buscou-se equilibrar a quantidade de sujeitos em um valor aproximado de 40 , distribuídos de forma balanceada entre indivíduos do sexo feminino e masculino, e entre seis faixas etárias. O número desejado de participantes foi escolhido com a finalidade de garantir uma população mínima para um tratamento estatístico dos dados.

\begin{tabular}{c|l|c}
\hline Características & \multicolumn{2}{c}{ Número desejado de participantes } \\
\hline \multirow{2}{*}{ Tipo de Participante } & Piloto & 5 \\
\cline { 2 - 3 } & Regular & 35 \\
\hline \multirow{2}{*}{ Sexo } & Total de Participantes & 40 \\
\hline \multirow{3}{*}{ Faixa Etária } & Feminino & 20 \\
\hline & Masculino & 20 \\
\hline & 18 a 24 & 10 \\
\hline & 25 a 34 & 10 \\
\hline & 35 a 44 & 8 \\
\hline & 45 a 54 & 8 \\
\hline & 55 a 64 & 2 \\
\hline & 65 ou mais & 2 \\
\hline
\end{tabular}

Quadro 1 - Amostra de características e número desejado dos participantes do Teste de Compreensão Iconográfica.

Outros critérios seriam registrados para posterior análise, em razão de identificar uma potencial influência de variáveis intervenientes nos resultados da pesquisa. Para tanto, propôs-se a coleta de dados referentes às áreas de formação acadêmica dos sujeitos, à experiência no uso de computadores e smartphones, e de seus respectivos sistemas operacionais, dentre outras variáveis. $16^{\circ}$ Ergodesign - Congresso Internacional de Ergonomia e Usabilidade de Interfaces Humano Tecnológica: Produto, Informações Ambientes Construídos e Transporte

$16^{\circ}$ USIHC - Congresso Internacional de Ergonomia e Usabilidade de Interfaces Humano Computador

CINAHPA | 2017 - Congresso Internacional de Ambientes Hipermídia para Aprendizagem.

\begin{tabular}{|c|c|c|}
\hline \multicolumn{3}{|c|}{ Variáveis Intervenientes } \\
\hline \multirow{3}{*}{$\begin{array}{l}\text { Escolaridade (Nível } \\
\text { Superior Completo e } \\
\text { Incompleto) }\end{array}$} & Ciências Biológicas & $\begin{array}{l}\text { Ciências Biológicas; } \\
\text { Ciências da Saúde; } \\
\text { Ciências Agrárias }\end{array}$ \\
\hline & Ciências Exatas & $\begin{array}{l}\text { Ciências Exatas e da } \\
\text { Terra; Engenharias }\end{array}$ \\
\hline & Ciências Humanas & $\begin{array}{l}\text { Ciências Sociais } \\
\text { Aplicadas; } \\
\text { Linguística, Letras e } \\
\text { Artes }\end{array}$ \\
\hline \multicolumn{2}{|r|}{ Uso do Computador } & Tempo em anos \\
\hline \multicolumn{2}{|r|}{ Uso de Smartphone } & Tempo em anos \\
\hline \multicolumn{2}{|c|}{ Sistemas Operacionais Utilizados } & $\begin{array}{l}\text { Quais? (De } \\
\text { Computador e } \\
\text { Smartphone) }\end{array}$ \\
\hline $\begin{array}{c}\text { Uso de Demais } \\
\text { Dispositivos Digitais }\end{array}$ & \multicolumn{2}{|c|}{$\begin{array}{l}\square \text { Câmera Digital; } \\
\square \text { Tocador de Mídia Portátil - MP3 e/ou } \\
\text { MP4/MTV Player; } \\
\square \text { Assistente Pessoal Digital - PDA, } \\
\text { Handheld ou Palmtop); } \\
\square \text { Receptor/Navegador GPS; } \\
\square \text { Leitores de Livros Eletrônicos; } \\
\square \text { Tablet e/ou Phablet; } \\
\square \text { TV Digital; } \\
\square \text { SmartTV; } \\
\square \text { Streaming de Mídia Digital; } \\
\square \text { Reprodutor de Mídia Digital; } \\
\square \text { TV OnDemand; } \\
\square \text { Outros. Quais? }\end{array}$} \\
\hline
\end{tabular}

Quadro 2 - Amostra de variáveis intervenientes dos participantes do Teste de Compreensão Iconográfica.

\section{2 Ícones Selecionados}

Para a seleção dos ícones a serem testados, decidiu-se por uma pré-seleção de variantes dentre os anos de 1984 - em decorrência dos primeiros sistemas operacionais da Apple e da Microsoft, - e 2005 [COMPUTER HISTORY MUSEUM, 2016]. $\mathrm{O}$ ano final determinado nessa pré-seleção se deve ao fato de que as versões seguintes desses sistemas foram lançadas apenas em 2007, período em que programas e aplicações equivalentes voltados a smartphones entraram ou começariam a entrar em circulação, influenciando nos repertórios visuais dos indivíduos. 


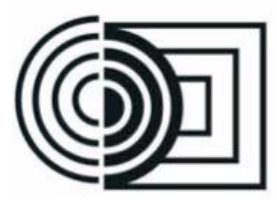

$16^{\circ}$ Ergodesign - Congresso Internacional de Ergonomia e Usabilidade de Interfaces Humano Tecnológica: Produto, Informações Ambientes Construídos e Transporte

$16^{\circ}$ USIHC - Congresso Internacional de Ergonomia e Usabilidade de Interfaces Humano Computador

CINAHPA | 2017 - Congresso Internacional de Ambientes Hipermídia para Aprendizagem.

\begin{tabular}{|c|c|c|}
\hline Referentes & Apple & Microsoft \\
\hline Aplicações & & \\
\hline Contatos & & \\
\hline Desligar & & \\
\hline Ferramentas & & \\
\hline Ajuda & & \\
\hline Lixeira Cheia & & \\
\hline Lixeira & & \\
\hline Bloco de Notas & & \\
\hline Pesquisar & & \\
\hline Configurações & & \\
\hline Sistema & & \\
\hline Calculadora & & \\
\hline Data e Hora & & \\
\hline Monitor & & \\
\hline E-mail & & \\
\hline $\begin{array}{l}\text { Gerente de } \\
\text { Aplicações }\end{array}$ & & \\
\hline Impressora & & \\
\hline Mouse & & \\
\hline Som & & \\
\hline Teclado & 国国 & s \\
\hline
\end{tabular}

Quadro 3 - Seleção final de 40 ícones da Apple e da Microsoft e seus referentes.

Havia uma profusão de referentes passíveis de seleção para o teste, porém, estes não se encontravam em quantidade equilibrada entre os sistemas da Apple e da Microsoft. Portanto, foram definidos apenas 20 deles, presentes em ambas as plataformas, com atribuições que variavam entre
Aplicativos, Configurações, Sistema, Inicialização e/ou Desligamento do computador. A escolha de uma variante por plataforma deu-se com base no Método de Pré-Seleção abordado por Formiga [2002]: dentre cada referente, escolheu-se os elementos gráficos díspares e, por fim, os com melhor legibilidade dentre os semelhantes.

\subsection{Procedimentos}

As sessões do Teste de Compreensão foram elaboradas para ocorrerem de modo remoto, no formato on-line - decisão tomada após a realização de testes piloto. Nestes, constatou-se que o modo presencial off-line dificultava o cômputo das respostas e incentivava que os sujeitos dialogassem com o moderador em busca de ajuda. Por esses motivos, optou-se pela utilização do software de pesquisa Eval\&GO ${ }^{1}$. A escolha dessa aplicação foi por tratar-se de um site com as opções de formulário específicas às necessidades do teste.

No início de cada sessão, ao acessar o link disponibilizado para o teste, o participante era apresentado quanto: à natureza da pesquisa, ao objetivo do teste e aos benefícios e riscos que poderiam ser acarretados na realização do mesmo. Foi enfatizada que a participação do sujeito seria voluntária e que, ao acessar o botão disponível para prosseguir, o indivíduo manifestaria concordância aos termos citados. Na página seguinte, o participante deveria responder a um questionário sociodemográfico, com questões referentes: à faixa etária; ao sexo; ao nível de escolaridade; e ao tempo de uso de computadores e smartphones e de seus respectivos sistemas operacionais.

Os participantes foram apresentados ao procedimento para realização do teste, devendo expressar por escrito, em uma caixa de texto, o significado de cada ícone exposto, de acordo com interpretação própria. Os sujeitos tiveram 20 segundos para cada ícone apresentado, dispostos um por página, e randomizados a cada participante. Limitou-se o tempo de resposta com a finalidade de dificultar as chances de consulta durante o teste.

${ }^{1}$ Eval\&GO: http://www.evalandgo.pt/
Realização:
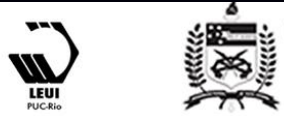


\section{$16^{\circ}$ \\ ERGODESIGN USIHC CINAHPA}

Os dados coletados por meio do teste foram: as características gerais dos participantes, via um questionário; e as respostas destes quanto ao significado de cada um dos 40 ícones apresentados. As respostas coletadas por meio do teste foram avaliadas para segregar a amostra de participantes em dois grupos de controle: o dos participantes com notas acima da média e os dos com nota abaixo da média. Para essa análise, pontuou-se as respostas como: acertos, contabilizando 2 pontos; meio acertos, 1 ponto; erros; e sem resposta, ambos sem pontuar (nenhum ponto, ou zero). A pontuação máxima possível alcançada por cada indivíduo era de 80 pontos.

Como exemplos de análise de dados, têm-se os referentes "Data e Hora" e "Monitor" apresentados em seguida, dos quais considerou-se como meio acertos as respostas que se associavam parcialmente aos seus significados, e como erros as que em pouco ou nada combinavam com as propostas dos ícones. Os dados foram computados em uma planilha no software Microsoft Office Excel 2016.

\begin{tabular}{|c|c|c|c|c|}
\hline Ícone & Referente & Acerto & Meio acerto & Erro \\
\hline \begin{tabular}{|c|c|c|c|}
\hline 23 \\
\hline
\end{tabular} & Data e Hora & $\begin{array}{c}\text { Configurações } \\
\text { de Data/Hora }\end{array}$ & Calendário & Volume \\
\hline & Monitor & $\begin{array}{c}\text { Configurações } \\
\text { de Tela }\end{array}$ & $\begin{array}{c}\text { Ajuste de } \\
\text { Cores }\end{array}$ & Limpar \\
\hline
\end{tabular}

Quadro 4 - Exemplos de análises do Teste de Compreensão Iconográfica.

A computação das respostas foi seguida pela elaboração de um histograma, o que permitiria uma realização posterior de Análises de Variância (ANOVAs). O teste de ANOVA tem como objetivo testar a hipótese de que as médias de duas ou mais populações são similares. A hipótese nula $\left(\mathrm{H}_{0}\right)$ afirma que todas as médias das populações são iguais, enquanto a hipótese alternativa $\left(\mathrm{H}_{1}\right)$ afirma que pelo menos uma é diferente [WICKENS et al., 1997; MARTINS e FONSECA, 2010]. Neste estudo, a decisão em utilizar esse procedimento partiu da necessidade de averiguar o impacto das variáveis sociodemográficas no resultado final do Teste de Compreensão, isto é, no repertório visual dos sujeitos da pesquisa. Ademais, o tratamento estatístico dos dados obtidos nesse teste permitiu $16^{\circ}$ Ergodesign - Congresso Internacional de Ergonomia e Usabilidade de Interfaces Humano Tecnológica: Produto, Informações Ambientes Construídos e Transporte

$16^{\circ}$ USIHC - Congresso Internacional de Ergonomia e Usabilidade de Interfaces Humano Computador

CINAHPA | 2017 - Congresso Internacional de Ambientes Hipermídia para Aprendizagem. agrupar os participantes em dois extremos, uma segregação indispensável ao Teste de Usabilidade aplicado em etapa posterior.

\section{Resultados}

O Teste de Compreensão Iconográfica foi aplicado remotamente, via um questionário on-line, no período entre os meses de setembro e outubro de 2016. Foram avaliados os repertórios visuais de um total de 48 participantes, sendo 24 do sexo masculino e 24 do feminino, de seis faixas etárias distintas, partindo de 18 anos. Como previsto no plano de teste, todos afirmaram ser usuários de smartphones e possuir nível de escolaridade mínimo superior completo ou cursando, em qualquer área.

\subsection{Classificação dos Participantes}

Diante de cada ícone, os participantes deveriam conjecturar quanto aos affordances do elemento apresentado, ou seja, indicar o caminho da interação para onde o usuário seria direcionado caso clicasse/tocasse no ícone. Como resultado, os sujeitos foram julgados em sua compreensibilidade visual, sendo agrupados por notas quanto à Alfabetização Visual e ao repertório no âmbito digital. Uma análise estatística foi realizada por meio da construção de um histograma [MARTINS e FONSECA, 2010], em que se fez possível destacar os participantes agrupados nos extremos da amostra. O histograma é um gráfico para visualização da distribuição de dados, que apresenta agrupamentos de um conjunto de dados em células, usualmente representadas por barras. A "altura" de cada célula é dada pela quantidade de vezes - ou frequência - em que os valores aparecem na amostra. Na sequência, é possível identificar que a base de cada retângulo representa uma classe (nota no teste), e a altura a frequência (quantidade de participantes) com que o valor dessa classe ocorreu no conjunto de dados. 
$16^{\circ}$ Ergodesign - Congresso Internacional de Ergonomia e Usabilidade de Interfaces Humano Tecnológica: Produto, Informações Ambientes Construídos e Transporte

$16^{\circ}$ USIHC - Congresso Internacional de Ergonomia e Usabilidade de Interfaces Humano Computador

CINAHPA | 2017 - Congresso Internacional de Ambientes Hipermídia para Aprendizagem.

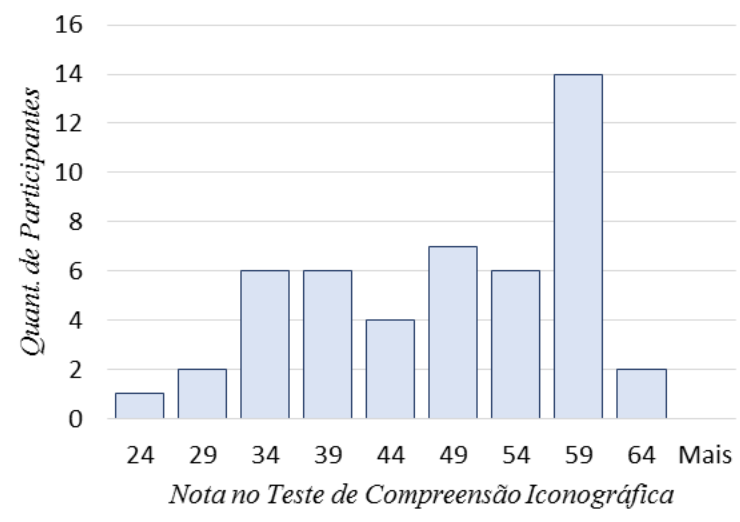

Gráfico 1 - Histograma da Quantidade de Participantes versus Notas no Teste de Compreensão Iconográfica.

Uma vez que os dados dos participantes foram armazenados e tratados em planilhas, fez-se essencial verificar a normalidade da distribuição dos dados do histograma por meio de um Teste KS (Kolmogorov-Smirnov). O resultado desse teste indicou que a distribuição é Normal, permitindo, portanto, inferências estatísticas paramétricas. A distribuição Normal é a distribuição de probabilidade mais importante, e muito utilizada para o desenvolvimento teórico da estatística [MARTINS e FONSECA, 2010]. Após o tratamento estatístico, fez-se possível destacar os participantes agrupados nos extremos da amostra, ou seja, os com nota no Teste de Compreensão que, a partir da média $(46,5416)$, estão acima ou abaixo do desvio padrão $(10,6330)$, como mostra o gráfico em destaque. Para facilitar a menção desses dois grupos no decorrer da pesquisa, optou-se por denominá-los como participantes com baixo e alto rendimento. Foram identificados 11 participantes com baixo rendimento (notas $<35,9086$ ) e $7 \mathrm{com}$ alto (notas $>57,1746)$.

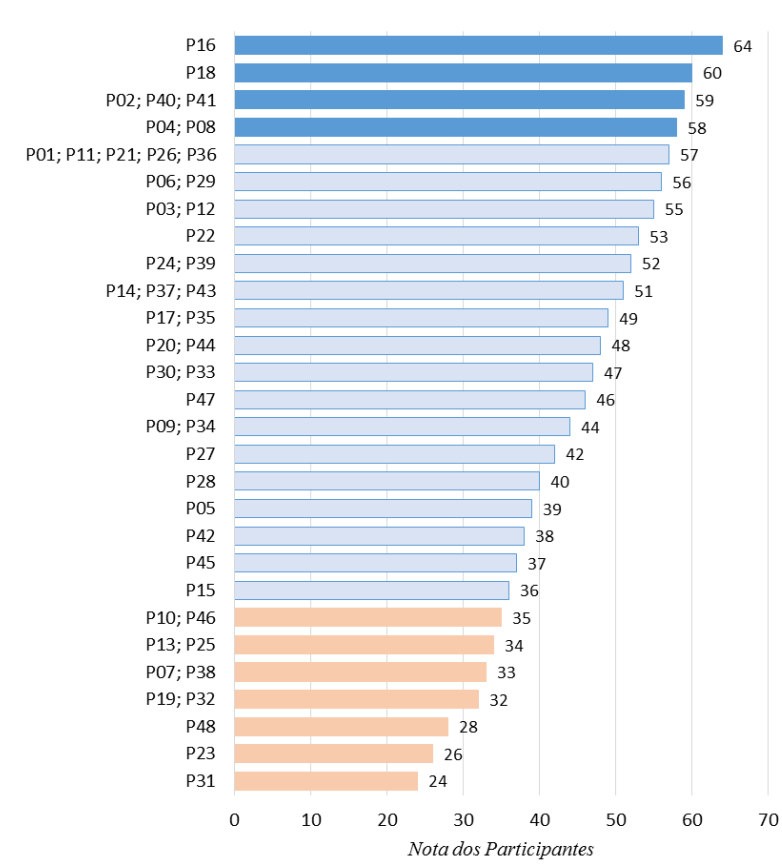

Gráfico 2 - Segmentação dos participantes do Teste de Compreensão em extremos de alto e de baixo rendimento, e, ao centro, de rendimento médio.

Uma vez avaliados os repertórios visuais dos sujeitos, sendo parte destes classificados em dois grupos extremos, mensurou-se como a variável Alfabetização Visual difere para grupos distintos de pessoas. Nessa conjuntura, os dados foram avaliados por meio de ANOVAs.

\subsection{Análises de Variância (ANOVAs)}

A literatura diverge quanto à noção de que há diferenças significativas de cognição entre usuários no que cerne ao hiato etário: para Prensky [2001a, 2001b, 2009], existe uma dicotomia de usuários Nativos e Imigrantes Digitais, havendo uma disparidade entre gerações no que diz respeito aos padrões de pensamento, uma visão refutada por demais autores [STOERGER, 2009; THOMAS, 2011]. De acordo com Prensky [2001a], aqueles indivíduos que imersos desde o nascimento no meio digital são chamados Nativos Digitais. Eles, como resultado da ubiquidade do ambiente digital e da interação plena com este, pensam e processam informações de modo diferente do de seus antecessores. Entre as características do Nativo deduz-se que esse usuário possui total fluência no meio digital, visto considerar telefones celulares, 


\section{$16^{\circ}$ \\ ERGODESIGN USIHC CINAHPA}

computadores portáteis e demais dispositivos multimídia como uma parte natural da vida cotidiana [CARNE, 2011]. Em contrapartida ao usuário fluente, têm-se os Imigrantes Digitais, usuários que, segundo Carne [2011, p. 3, tradução nossa] "[...] buscam imitar os modos dos nativos digitais [...]". Pertencente a uma geração anterior, o Imigrante é aquele que, em algum estágio da vida, tornou-se fascinado por e adotou muitos ou a maioria dos aspectos das novas tecnologias. Para Prensky [2001a], a importância em se distinguir tais arquétipos de usuários está em legitimar a percepção de que os imigrantes digitais, enquanto aprendem a se adaptar ao meio digital, sempre mantêm, em algum grau, certo "sotaque". Isto ocorre porque, para o autor, os Imigrantes foram socializados de modo diferente ao de seus sucessores fluentes, e encontram-se num processo semelhante ao de aprender uma nova língua.

Tendo em vista o Teste de Compreensão como um medidor viável da Alfabetização Visual dos participantes relacionada a referentes no meio digital, fez-se possível averiguar se as médias das populações de Nativos e Imigrantes são iguais ou diferentes. Dos 48 sujeitos do teste, 29 se encaixam no conceito de Nativos, considerando suas idades entre 18 e 34 anos. Os 19 sujeitos restantes são tidos como Imigrantes Digitais, com idades a partir de 35 anos, como apontam os gráficos:

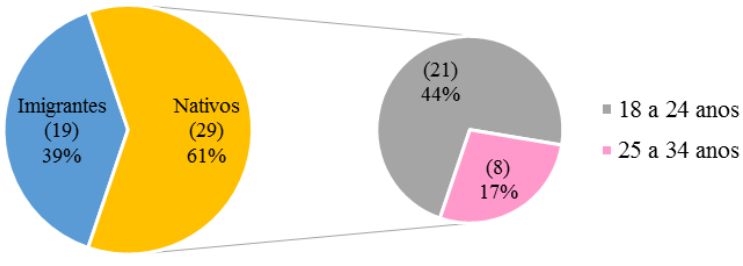

Gráfico 3 - Quantidade de participantes Nativos Digitais por faixa etária $(n=48)$.

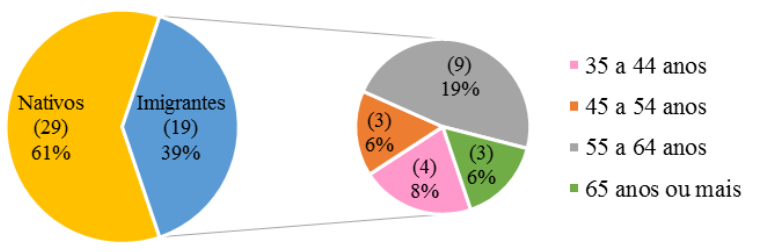

Gráfico 4 - Quantidade de participantes Imigrantes Digitais por faixa etária $(n=48)$. $16^{\circ}$ Ergodesign - Congresso Internacional de Ergonomia e Usabilidade de Interfaces Humano Tecnológica: Produto, Informações Ambientes Construídos e Transporte

$16^{\circ}$ USIHC - Congresso Internacional de Ergonomia e Usabilidade de Interfaces Humano Computador

CINAHPA | 2017 - Congresso Internacional de Ambientes Hipermídia para Aprendizagem.

De acordo com o teste de ANOVA - para efeito de organização, ANOVA “a” - pode-se afirmar, com $95 \%$ de certeza, que

a) Há diferenças significativas entre as notas de indivíduos Nativos e Imigrantes no Teste de Compreensão Iconográfica (valor-p $=0,035$ ), o que corrobora ao menos parcialmente com a percepção de Prensky [2001a, 2001b, 2009].

Haja vista que as ANOVAs testam a hipótese $\left(\mathrm{H}_{0}\right)$ de que há igualdade entre as distribuições, ou seja, que as médias de duas ou mais populações são similares, para determinar se há diferenças entre essas médias, e que essas diferenças são estatisticamente significativas, deve-se comparar o valor $-p$ com o nível de significância, $\alpha=0,05$. Se o valor-p for menor ou igual ao $\alpha$, rejeita-se a hipótese nula $\left(\mathrm{H}_{0}\right)$, ou seja, conclui-se que nem todas as médias da população são iguais. Portanto, a análise apontou que a média das notas dos Nativos ultrapassou a dos Imigrantes (valor $-\mathrm{p}=$ $0,035<0,05)$, isto é, que os participantes com 34 anos ou menos tiveram, no geral, um melhor desempenho no teste do que os seus antecessores.

Após essa conclusão preliminar, buscou-se aferir se outras variáveis são passíveis de exercer influência nos níveis de Alfabetização Visual relacionada a referentes no meio digital. Com os testes de ANOVA "b", "c", e "d", concluiu-se que a mesma disparidade de resultados acontece no que diz respeito:

b) Às notas dos indivíduos pré-idosos (de 55 a 64 anos) e idosos (65 anos ou mais) em relação às dos demais sujeitos (valor- $\mathrm{p}=0,004$ );

c) Às notas dos usuários exclusivos de Windows em relação às dos usuários de Windows e de outros sistemas operacionais (valor- $\mathrm{p}=0,01$ );

d) $\mathrm{E}$ às notas dos indivíduos com formação em Design em relação às notas dos com formação em outras áreas (valor- $\mathrm{p}=0,02$ ).

No tocante à questão dos pré-idosos e idosos $(\mathbf{b})$, já era dedutível que o resultado da ANOVA estaria de acordo com a afirmação sobre as médias de Nativos e Imigrantes, cuja causa provável é o hiato etário. Porém, cabem inferências relativas aos
Realização:

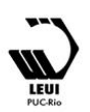




\section{$16^{\circ}$ \\ ERGODESIGN USIHC CINAHPA}

resultados obtidos em "c" e "d", visto a literatura abordar questões que respaldam essas discrepâncias. Quando se fala em Alfabetização Visual, discute-se como ela está profundamente associada aos repertórios visuais individuais, e que estes, por sua vez, podem ser específicos de determinados grupos ou comunidades dentro de uma mesma cultura [POTTER, 1996; LAPENTA, 2005]. Partindo do fato de que esta pesquisa trabalhou com o conceito de repertórios visuais no âmbito digital, é compreensível que os participantes expostos a sistemas operacionais distintos - e consequentemente a diferentes GUIs possuam um repertório maior do que os sujeitos com contato único com o sistema Microsoft Windows (Gráfico 5). Essa mesma inferência pode ocorrer no que concerne aos sujeitos com formação em Design, que obtiveram um melhor desempenho do que os de demais áreas de formação (Gráfico 6).

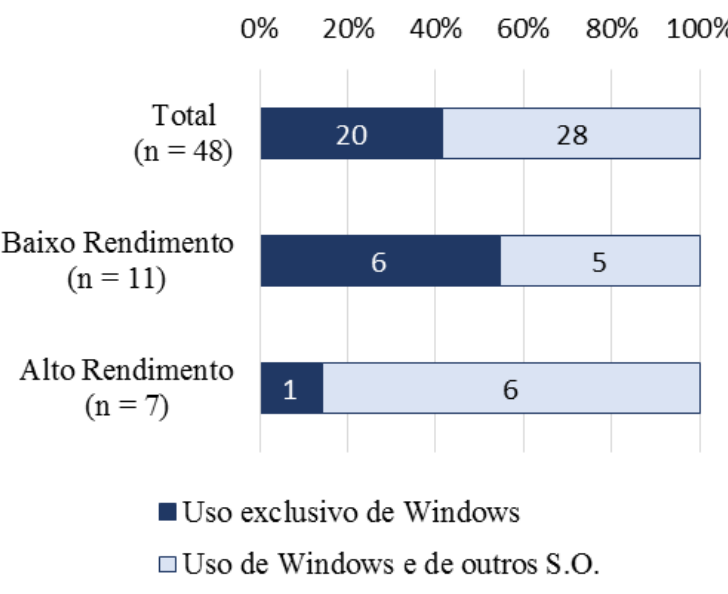

Gráfico 5 - Comparativo dos percentuais de usuários exclusivos de Windows versus usuários de Windows e de outros sistemas operacionais (S.O.): relação total de participantes; participantes de baixo rendimento; e de alto rendimento. $16^{\circ}$ Ergodesign - Congresso Internacional de Ergonomia e Usabilidade de Interfaces Humano Tecnológica: Produto, Informações Ambientes Construídos e Transporte

$16^{\circ}$ USIHC - Congresso Internacional de Ergonomia e Usabilidade de Interfaces Humano Computador

CINAHPA | 2017 - Congresso Internacional de Ambientes Hipermídia para Aprendizagem.

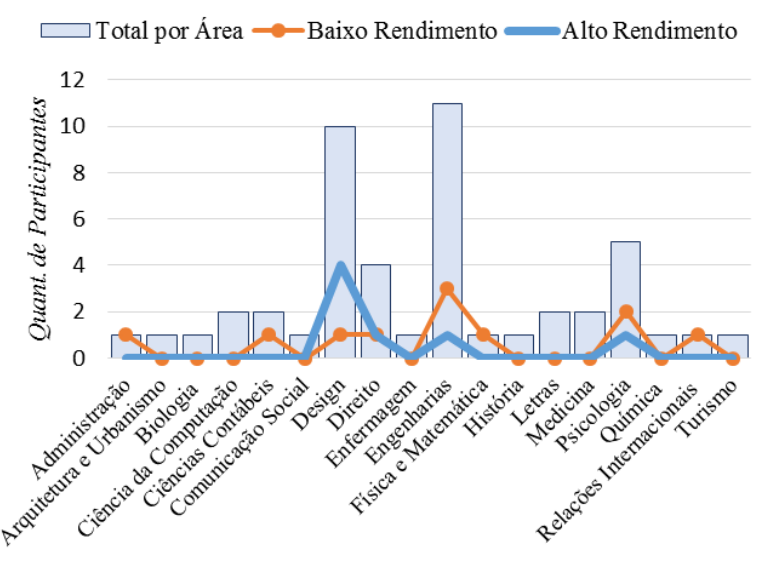

Gráfico 6 - Participantes do Teste de Compreensão agrupados por áreas de formação $(n=48)$.

Análises de Variância também foram feitas a partir de outras variáveis intervenientes fornecidas pelos sujeitos do teste. Os participantes foram inquiridos no que tange ao tempo de uso de computadores e smartphones; ao contato prévio ou atual com os sistemas operacionais desses dispositivos, quando houve; e à experiência com demais dispositivos digitais. Todavia, de acordo os testes de ANOVA, não há diferenças significativas nas médias dos participantes em relação a essas variáveis.

\section{Conclusão}

Por fim, o reconhecimento de padrões entre os participantes de características semelhantes ou idênticas respondeu às questões do Teste de Compreensão e comprovou haver uma relação entre certas variáveis intervenientes e a compreensão iconográfica por parte dos sujeitos da pesquisa. Todavia, essencialmente, este teste serviu como processo de recrutamento aos participantes do Teste de Usabilidade, cujas características foram devidamente delineadas em uma segunda etapa da pesquisa.

As mudanças constantes no cenário tecnológico, em especial as verificadas no contexto dos dispositivos de uso pessoal, intervêm diretamente no comportamento humano, influenciando como indivíduos interagem uns com os outros e com o mundo. $\mathrm{O}$ advento e a popularização dos computadores pessoais na década de 80 , por exemplo, atuaram como um marco temporal e um 


\section{$16^{\circ}$ \\ ERGODESIGN USIHC CINAHPA}

$16^{\circ}$ Ergodesign - Congresso Internacional de Ergonomia e Usabilidade de Interfaces Humano Tecnológica: Produto, Informações Ambientes Construídos e Transporte

$16^{\circ}$ USIHC - Congresso Internacional de Ergonomia e Usabilidade de Interfaces Humano Computador

CINAHPA | 2017 - Congresso Internacional de Ambientes Hipermídia para Aprendizagem. divisor entre gerações, sendo o fator geracional um importante catalizador dos diferentes níveis de proficiência dos usuários no âmbito digital.

Tendo em vista as evoluções tecnológicas, em sincronia com a prevalência da imagem - uma vez que se acessa grande parte das informações através de uma tela -, fez-se imprescindível discutir alfabetização para além do âmbito verbal. Em razão disso, constatou-se que a proficiência digital abrange um conjunto de habilidades, e, no que concerne à interação com interfaces gráficas, engloba uma Alfabetização Visual. É válido ressaltar que esta não se trata de um conhecimento superior ao das capacidades verbais do indivíduo, mas apenas um meio distinto de se comunicar em uma outra linguagem.

Enquanto o teste aqui discutido procurou elucidar como indivíduos com diferentes repertórios visuais compreendem os ícones de interfaces gráficas de dispositivos digitais, um Teste de Usabilidade subsequente buscou explorar como tais indivíduos utilizam seus respectivos repertórios visuais na interação com interfaces gráficas de aplicativos móveis.

Em conclusão, o Teste de Compreensão, bastante utilizado na Ergonomia Informacional, sofreu adaptações às necessidades da pesquisa, visto que, ao invés de avaliar elementos de interfaces e seus referentes, atuou na mensuração do desempenho dos participantes. Essa aplicabilidade se provou bem-sucedida em responder às questões do teste e da pesquisa, podendo ser utilizada em futuros estudos do gênero.

\section{BIBLIOGRAFIA}

CARNE, E. B. Connections for the Digital Age: Multimedia Communications for Mobile, Nomadic and Fixed Devices. John Wiley \& Sons, 2011.

COMPUTER HISTORY MUSEUM. Timeline of Computer History. 2016. Disponível em: $<$ http://www.computerhistory.org/timeline/comput ers/>. Acesso em: 22 set. 2016.
FORMIGA, E. de L. Avaliação de Compreensibilidade de Símbolos Gráficos Através de Métodos da Ergonomia Informacional. In: MORAES, Anamaria (org.). Avisos, Advertências e Projeto de Sinalização: Ergodesign

Informacional. Rio de Janeiro: iUsEr, p. 113-141, 2002.

\section{LAPENTA, F. The Image as a Form of}

Sociological Data: A Methodological Approach to the Analysis of Photoelicited Interviews. Tese de Doutorado. Goldsmiths College (University Of London), 2005.

MARTINS, G. de A.; FONSECA, J. S. da. Curso

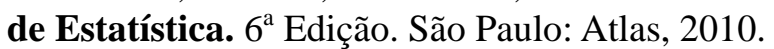

\section{NET MARKET SHARE. Mobile/Tablet}

Operating System Market Share. Market Share

Statistics for Internet Technologies, out. 2016.

Disponível em:

$<$ https://www.netmarketshare.com/operatingsystem-market-

share. aspx $?$ qprid $=8 \&$ qpcustomd=1 $>$. Acesso em: 10 nov. 2016.

POTTER, J. Discourse Analysis and Constructionist Approaches: Theoretical Background. In: RICHARDSON, J. T. E. (Ed). Handbook of Qualitative Research Methods for Psychology and the Social Sciences. Leicester: British Psychological Society, p. 125-140, 1996.

\section{PRENSKY, M. Digital Natives, Digital}

Immigrants. On the Horizon, v. 9, n. 5, p 1-6, 2001a.

Digital Natives, Digital Immigrants, Part 2: Do They Really Think Differently?. On the Horizon, v. 9, n. 6, p. 1-6, 2001b.

\section{H. Sapiens Digital: From Digital}

Immigrants and Digital Natives to Digital

Wisdom. Innovate: Journal of Online Education, v. 5, n. 3, p. 1, 2009. Disponível em:

<http://nsuworks.nova.edu/innovate/vol5/iss3/1/>. Acesso em: 10 fev. 2016.

STOERGER, S. The Digital Melting Pot: Bridging the Digital Native-Immigrant Divide.
Realização:

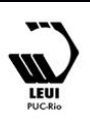




\section{$16^{\circ}$ \\ ERGODESIGN USIHC CINAHPA}

$16^{\circ}$ Ergodesign - Congresso Internacional de Ergonomia e Usabilidade de Interfaces Humano Tecnológica: Produto, Informações Ambientes Construídos e Transporte

$16^{\circ}$ USIHC - Congresso Internacional de Ergonomia e Usabilidade de Interfaces Humano Computador

CINAHPA | 2017 - Congresso Internacional de Ambientes Hipermídia para Aprendizagem.

In First Monday, v. 14, n. 7, 2009.

THOMAS, M. (Ed.). Deconstructing Digital

Natives: Young People, Technology, and the

New Literacies. Taylor \& Francis, 2011.

WICKENS, C. D.; GORDON, S. E.; LIU, Y. An

Introduction to Human Factors Engineering.

Addison Wesley Longman, 1997.

\section{Agradecimentos}

Ao CNPq e à CAPES, pelos auxílios concedidos.

À PUC-Rio e ao Departamento de Artes \& Design.

Aos participantes voluntários do Teste de

Compreensão Iconográfica, por se

disponibilizarem à aplicação do mesmo, e cuja

participação foi essencial à realização deste estudo. 